\title{
Influence of Welding Parameters on Microstructure and Mechanical Performance of Resistance Spot Welded High Strength Steels
}

\author{
H. Ghazanfari ${ }^{\dagger}$ and M. Naderi \\ Department of Mining and Metallurgical Engineering, Amirkabir University of Technology (Tehran Polytechnic), Tehran, \\ Iran \\ [Manuscript received 4 February 2013, in revised form 12 May 2013] \\ (c) The Chinese Society for Metals and Springer-Verlag Berlin Heidelberg
}

\begin{abstract}
This paper presents an experimental study on physical and mechanical properties of high strength steel plates (AISI 4130) joined by resistance spot welding by means of hardness mapping technique. Welding current and electrode force were selected as experimental parameters. The welded joints were exposed to tensile-shearing tests in order to determine the strength of the welded zones. Hardness and microstructural examinations were carried out in order to examine the influence of welding parameters on the welded joints. Hardness mapping test was conducted on the large area of weld zone, including the heat affected zone and base plate. Hardness map was used to investigate the effects of current on hardness and microstructure in different regions of weld. Low electrode force and high welding current, used during the welding, increased the expulsion. An optimum weld quality was obtained by using $6.5 \mathrm{kA}$ weld current. It was found that mechanical performance of resistance spot welded samples is controlled by nugget diameter and expulsion. Results revealed that hardness mapping technique provides one of the best methods for the physical and mechanical understanding of heterogeneous microstructures using hardness criterion.
\end{abstract}

KEY WORDS: Welding current; Microstructure; Hardness map; Expulsion; Martensite

\section{Introduction}

Heat-treatable low-alloy steels are widely used in marine industry because of its superior corrosion resistance and strength. Resistance spot welding is widely used to join sheet metals in the automotive industry. Welding current is the most important parameter in resistance spot welding. As current increases weld heat increases. The electrode force is also considered as an important feature during the resistance spot welding process due to its performance in the control of the quality of welding. Fusion zone size or nugget diameter and its microstructure are the most important parameters which affect the mechanical behavior of the spot welded samples. Since the mechanical properties of the steel are highly dependent on the microstructure, and distribution of each phase present

† Corresponding author. Prof., Ph.D.; Tel.: +98 21 64552978; Fax: +98 21 66405846; E-mail address: ghazanfari@aut.ac.ir (H. Ghazanfari)

DOI: $10.1007 / \mathrm{s} 40195-013-0076-1$ so, changing the welding current results into changing the mechanical properties. Some micro constituents produced during welding process have poor mechanical properties. For instance, the microstructure of untempered martensite has poor toughness. These microstructures are more detrimental when this particular microstructure has the predominant volume fraction in the weld. The hardness values of the weldment are used as an acceptance criterion for certain industrial applications. The hardness of the material is dependent on its microstructure. So, Hardness measurement would be a key quality assurance test, because it quickly defines whether the processing schedule has achieved the required characteristics. Moon et al. ${ }^{[1]}$ investigated the hardness changes on pass by pass basis in mild steel gas metal arc welds. In some reports, hardness maps were used to investigate the effects of welding process parameters on microstructure ${ }^{[2-4]}$. Naderi et al. ${ }^{[5,6]}$ used hardness mapping technique to investigate the heterogeneous microstructures. Numerous researchers investigated the effect of welding parameters on the joint strength 
Table 1 Chemical composition of 4130 steel

\begin{tabular}{cccccccccc}
\hline $\mathrm{C}$ & $\mathrm{Si}$ & $\mathrm{Mn}$ & $\mathrm{Cr}$ & $\mathrm{Mo}$ & $\mathrm{Cu}$ & $\mathrm{P}$ & $\mathrm{S}$ & $\mathrm{Ni}$ & $\mathrm{Fe}$ \\
\hline 0.305 & 0.25 & 0.5 & 0.95 & 0.2 & 0.17 & 0.012 & 0.012 & 0.125 & Balanced \\
\hline
\end{tabular}

Table 2 Resistance spot welding conditions for each specimen

\begin{tabular}{ccc}
\hline Specimen No. & Electrode force $(\mathrm{kN})$ & Welding current $(\mathrm{kA})$ \\
\hline 1 & 5 & 5 \\
2 & 5 & 5.5 \\
3 & 5 & 6 \\
4 & 5 & 6.5 \\
5 & 5 & 7 \\
6 & 5 & 7.5 \\
7 & 3.8 & 6.5 \\
8 & 4.4 & 6.5 \\
9 & 5 & 6.5 \\
10 & 5.6 & 6.5 \\
11 & 6.2 & 6.5 \\
12 & 6.8 & 6.5 \\
\hline
\end{tabular}

Note: welding time is 17 cycle, holding time is 30 cycle, squeez time is 40 cycle

of resistance spot welded ${ }^{[7-10]}$. Liao et al..$^{[11]}$ investigated the microstructures in a resistance spot welded high strength dual phase steel. Marashi et al..$^{12]}$ investigated the microstructure and failure behavior of dissimilar resistance spot welds. Pouranvari investigated the effect of fusion zone size and failure mode on mechanical performance of dissimilar resistance spot welds ${ }^{[13]}$.

The objective of present study is to investigate the effect of spot welding parameters on microstructure and mechanical properties within the welded samples and compare the results by means of the hardness maps.

\section{Experimental}

\subsection{Material preparation}

In this research $2 \mathrm{~mm}$ thick AISI 4130 steel sheets were used as the base metal and their surfaces were cleaned by $\mathrm{HCl}$ solution to eliminate surface contaminations. The sheets were then welded by resistance spot welding as a lap joint. The chemical composition of AISI 4130 steel is given in Table 1. Welding was conducted using a $45^{\circ}$ truncated cone RWMA, Class 2 electrode with $6 \mathrm{~mm}$ face diameter. The parameters used in the process are given in Table 2 .

The specimens were then polished and etched in a solution of $3 \% \mathrm{HNO}_{3}+$ ethanol and the microstructures were observed by light optical microscope (LOM). The welded parts were subjected to tensile-shear loads with the head speed of $1 \mathrm{~mm} / \mathrm{min}$ to determine the tensile- shear strength in a Santam STM-600 testing machine in laboratory as shown in Fig. 1.

\subsection{Hardness test specification}

Surface hardness measurements were started at

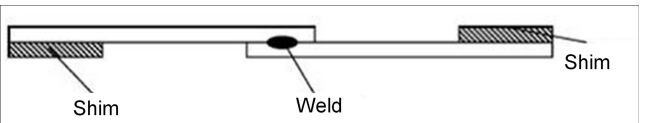

Fig. 1 Schematic for shear tensile samples ${ }^{[10]}$

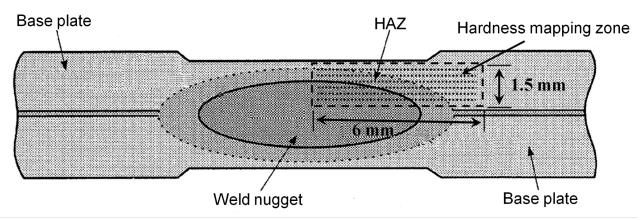

Fig. 2 Sketch of zone selected for the hardness test

$0.2 \mathrm{~mm}$ distance from the boundary between the mounting material and the sample due to the high hardness values of sample's edge. Surface hardness measurements were carried out using scanning hardness machine under the $1 \mathrm{~kg}$ load with $0.1 \mathrm{~mm}$ interval. Each sample was plotted by 900 indents $(60 \times 15)$. The location of the measurements is shown in Fig. 2.

\section{Results and Discussion}

\subsection{Microstructural characterizations}

Fig. 3 shows a typical macrostructure of a cross section of the weld including the hardness mapping indents. Three distinct microstructural zones can be seen in macroscopic image: weld, Heat Affected Zone (HAZ), and base plate.

Base plate temperatures during welding typically remain below $200{ }^{\circ} \mathrm{C}$ remote from the weld. So, no transformations are activated and the microstructural constituents are left unaffected ${ }^{[16]}$. Fig. 4 shows the microstructure of the base plate.

Fig. 5 shows the microstructures of the welds. The 


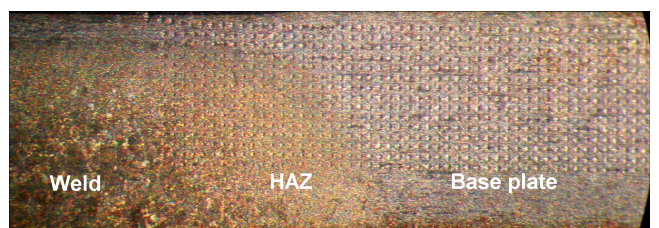

Fig. 3 The macroscopic image of the spot welded sample including the indents

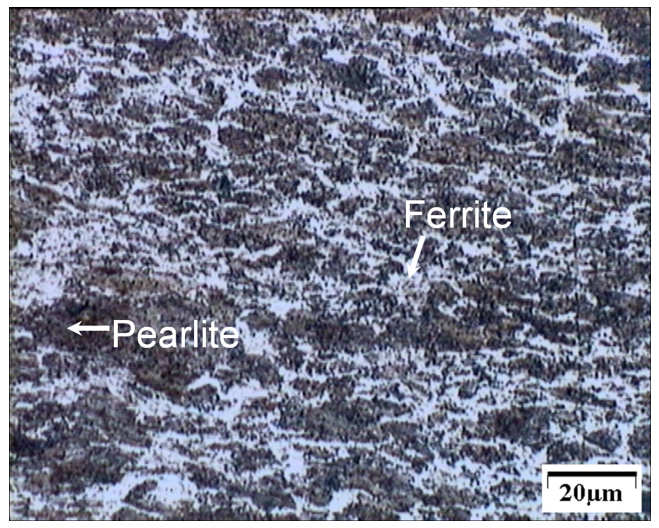

Fig. 4 The microstructure of the base plate

microstructures are mainly martensite. The weld zone is created by heating above the melting point, subsequent rapid cooling, the austenite transforms into martensite. As seen in Fig. 5, martensite with less Lath width was found in the weld fabricated with lower weld current. It is shown that due to the higher welding temperature at higher welding current, the lath width of the martensite with higher welding current will be larger than that in the weld zone.

To calculate the martensite lath width, several fields in the weld zone were taken and imaged by light optical microscopy. The lath width of the martensite was then determined. For each image 10 data were recorded. The average values were considered as the martensite lath width of the weld. Fig. 6 shows the effect of the welding current on the martensite's lath width.

Fig. 7 shows the microstructures of Intercritical HAZ (IC HAZ). Since, peak temperatures in the IC $\mathrm{HAZ}$ range is between Ac1 and Ac3 so, within this range, increasing peak temperature results in an increase in the fraction of ferrite dissolved in to austenite. Rapid post weld cooling can result in the transformation of inter critically austenitized grains back into a dual phase martensite-ferrite structure ${ }^{[16,17]}$. The typical IC HAZ microstructure comprised of undissolved ferrite and dispersed bainite islands ${ }^{[18]}$. The peak temperature is increased by increasing the welding current. This increases the fraction of the ferrite that was dissolved into austenite as seen in Fig. 7. The more dissolved ferrite into austenite, the less carbon content exists in the austenite. Since, carbon increases both the hardenability and hardness of the microstructure so, increasing the welding current in intercritical HAZ results in the increase of the volume fraction of the martensite or the bainite with lower hardness values.

\subsection{Hardness measurements}

Fig. 8 shows the hardness maps of different samples. The base plate has the lowest range of the hardness through the sample (190HV-250HV). The different sub regions of HAZ including the subcritical (SC), intercritical (IC) and upper critical heat affected zones can be seen in hardness map with different hardness ranges. Subcritical HAZ has the same hardness value as the base plate. Intercritical HAZ is specified by the hardness between $250 \mathrm{HV}-325 \mathrm{HV}$ and upper critical has a hardness values between $325 \mathrm{HV}-400 \mathrm{HV}$.

It was found that in weld zone the average hardness value decreases by increasing the welding current. It was also found that increasing welding current leads to extending of the weld zone up to $6.5 \mathrm{kA}$. The expulsion considered as defect in resistance spot welding was appeared in hardness maps by increasing the welding current beyond $6.5 \mathrm{kA}$. Expulsion decreases nugget diameter due to heat loss which occurs when a volume of melt is expelled from the weld nugget ${ }^{[19]}$ (Fig. 8).

450 data points from specimens' weld zone were used to prepare the Table 3. Examination of the weld samples clearly shows the softening phenomenon by increasing the welding current. A significant part of the weld in sample 1 has a hardness values higher than

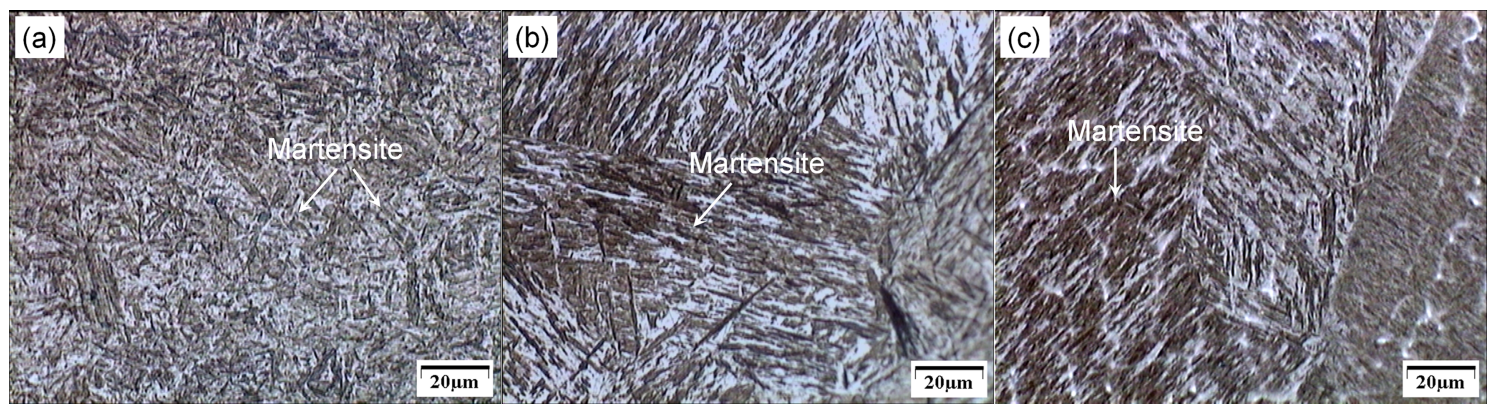

Fig. 5 Microstructures of welds by light optical microscopy: (a) $5.5 \mathrm{kA}$, (b) $6.5 \mathrm{kA}$, (c) $7.5 \mathrm{kA}$ 


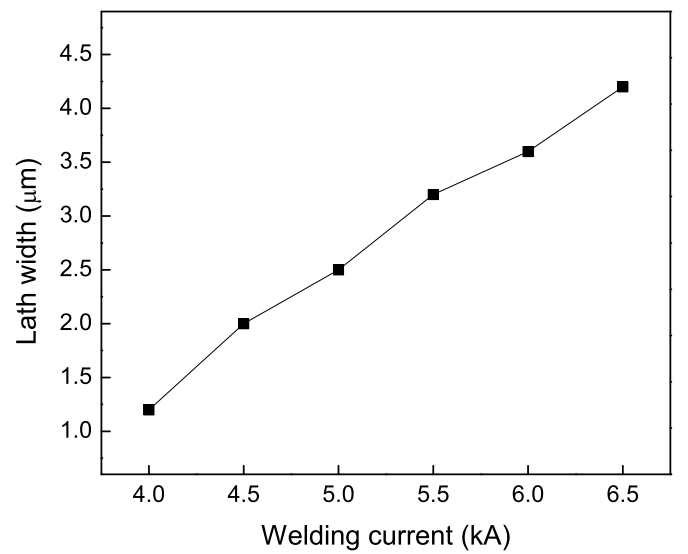

Fig. 6 Effect of the welding current on the lath width

$500 \mathrm{HV}$. It is illustrated that Vickers hardness values higher than $500 \mathrm{HV}$ just exist in the weld of sample1 and sample 2. Increasing the welding current reduces the number of hardness values higher than $450 \mathrm{HV}$ considerably. In sample 4, only a few hardness values exceed the $450 \mathrm{HV}$. The significant part of sample 4 has the hardness values between $400 \mathrm{HV}-450 \mathrm{HV}$. As can be seen the number of hardness values between $350 \mathrm{HV}-400 \mathrm{HV}$ increases by increasing the current. The significant part of the weld metal in sample 5 has the hardness values $<400 \mathrm{HV}$. In sample 6 only a very few hardness values exceeded $400 \mathrm{HV}$. A schematic of the hardness range of different samples' weld is shown in Fig. 9.

\subsection{Effects of the welding current and electrode force on nugget size and tensile-shear strength}

Fig. 10 and Fig. 11 show the effects of the welding current and the electrode force on the nugget diameter and tensile-shear force. The effect of the electrode force on the nugget size can be illustrated relative to the basic heat equation used in resistance welding;

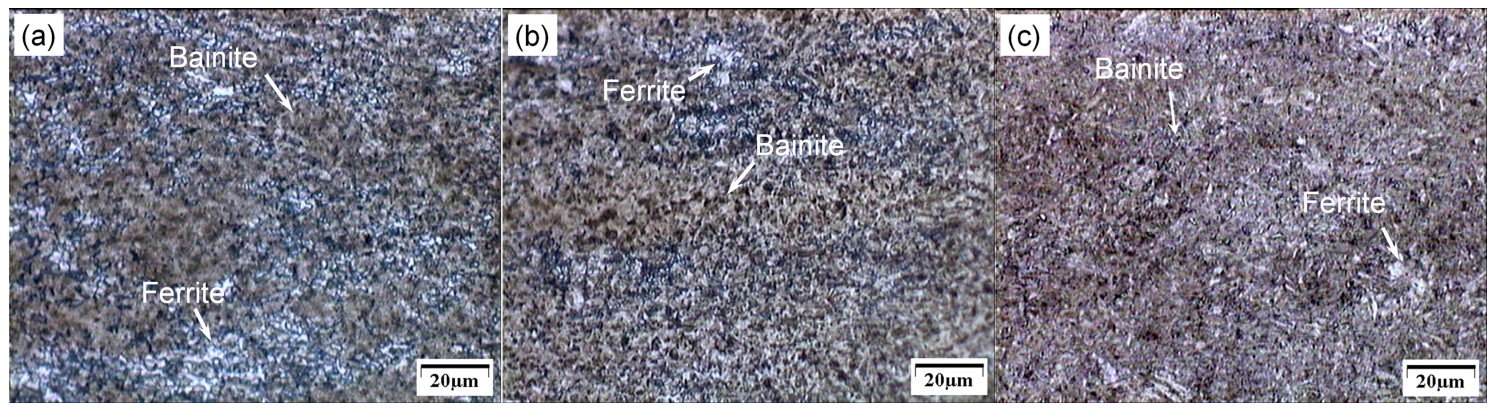

Fig. 7 Microstructures of IC HAZ obtained by light optical microscopy: (a) $5.5 \mathrm{kA}$, (b) $6.5 \mathrm{kA}$, (c) $7.5 \mathrm{kA}$
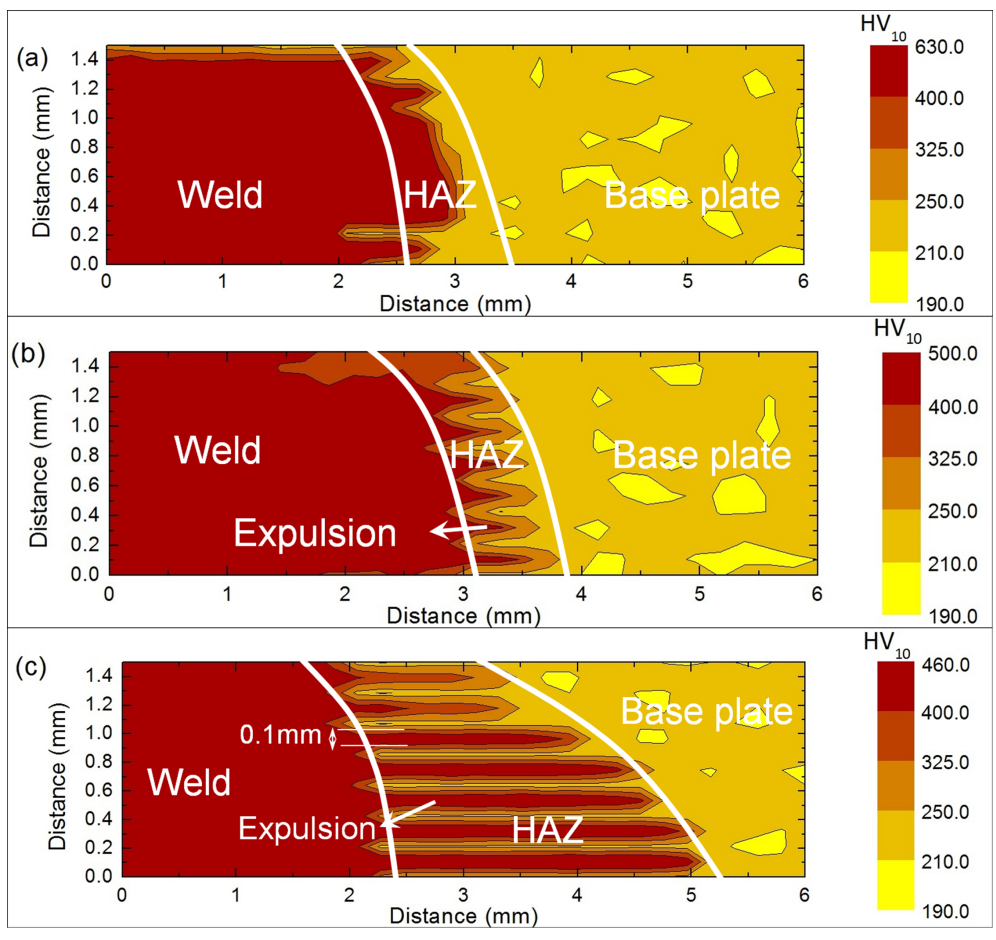

Fig. 8 Hardness maps of the samples: (a) $5.5 \mathrm{kA}$, (b) $6.5 \mathrm{kA}$, (c) $7.5 \mathrm{kA}$ 
Table 3 The hardness data from weld zones

\begin{tabular}{ccccccc}
\hline Specimen No. & \multicolumn{7}{c}{ Hardness range (HV) } \\
\cline { 2 - 7 } & $250-300$ & $300-350$ & $350-400$ & $400-450$ & $450-500$ & $>500$ \\
\hline 1 & - & 14 & 34 & 86 & 121 & 195 \\
2 & 10 & 30 & 69 & 106 & 157 & 78 \\
3 & 25 & 46 & 66 & 145 & 168 & - \\
4 & 21 & 71 & 124 & 226 & 8 & - \\
5 & 20 & 132 & 228 & 70 & - & - \\
6 & 51 & 148 & 245 & 6 & - & - \\
\hline
\end{tabular}

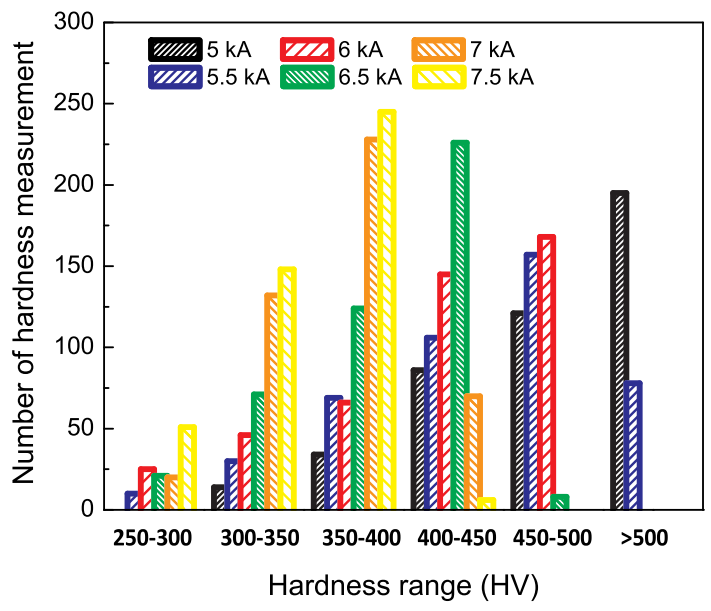

Fig. 9 Hardness data from the weld zones

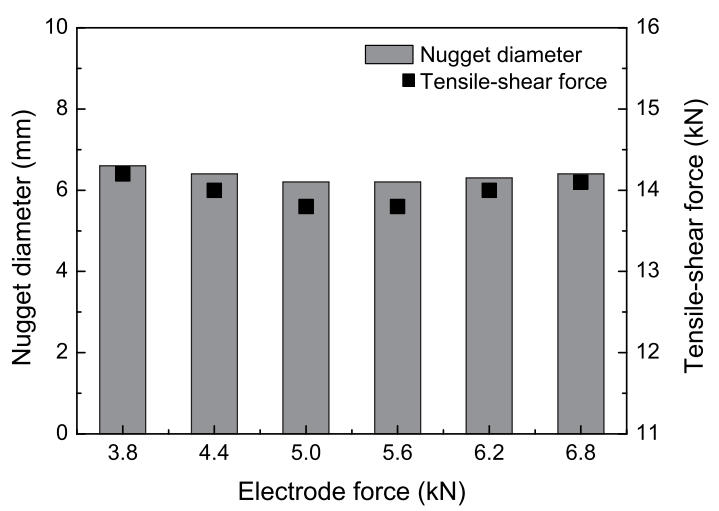

Fig. 10 Effect of the electrode force on the nugget diameter and the tensile-shear strength

i.e. $H=I^{2}$ Rt. Low electrode force will increase the resistance factor $\mathrm{R}$ of this equation. While a high resistance caused by a low force will generate more heat, the negative effects of metal expulsion ${ }^{[20]}$.

As can be seen in Fig. 10 at low electrode forces, the weld nugget diameter slightly decreases with increasing electrode force. This should be ascribed by the fact that at low electrode forces values, the weld nugget diameter is slightly less than the expected values because of the expulsion of the metal from the weld nugget. This effect is not strict as the effect of the welding current, because of the equation $H=I^{2} R t$. In this equation heat is directly proportional to the resistance itself but to the square of the current. Hence, as the welding current increases, there is a sudden

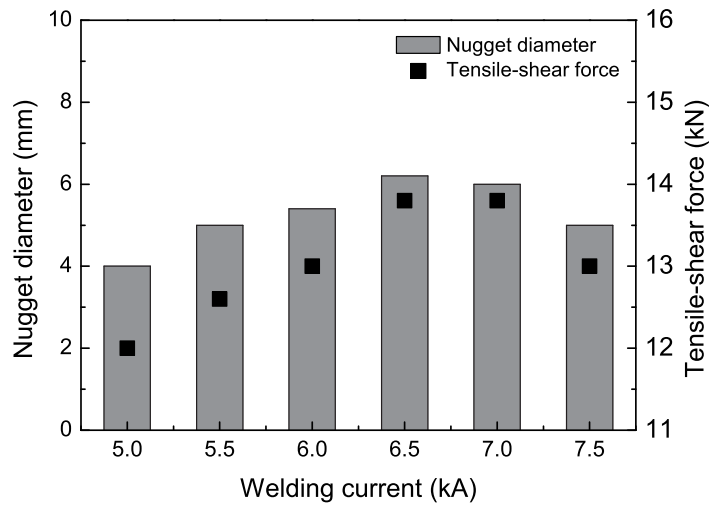

Fig. 11 Effect of the welding current on the nugget diameter and the tensile-shear strength

rise in the weld nugget diameter. This situation is seen in Fig. 11. But, it should be noted that for the welding current range of $7.5 \mathrm{kA}$, there is a decrease in the weld nugget diameter due to the expulsion that is most probable for such a high welding current range. Because of the expulsion the weld nugget diameter decreases rapidly. Similar results were obtained by Hasanbasoglu et al. ${ }^{[21]}$ and Ozyurek et al. ${ }^{[9]}$ for austenitic stainless steel and Aslanlar et al. ${ }^{[7]}$ for galvanized chromided steel sheets.

\section{Conclusions}

(1) The increase in the welding current caused coarsening of the microstructure of the weld zone and decreasing the region with hardness higher than $400 \mathrm{HV}$.

(2) The number of the hardness values between $300-400 \mathrm{HV}$ increased by increasing welding current.

(3) Higher welding current caused the less ferrite microstructure in IC HAZ.

(4) The maximum tensile-shear strength value was obtained at $6.5 \mathrm{kA}$ due to the enlargement of the nugget size. Beyond this current, tensile shear strength decreased due to the expulsion effect which leads to decreasing the nugget diameter.

(5) Low electrode force and high welding current, used during the welding process increased the expulsion and decreased nugget diameter consequently.

\section{REFERENCES}

[1] D.W. Moon, S.G. Lambrakos, R.J. Wong and E.A. Metzbower, Sci. Technol. Weld. Join. 8 (2003) 95. 
[2] D.W. Moon, S.G. Lambrakos, R.J. Wong and E.A. Metzbower, Sci. Technol. Weld. Join. 8 (2003) 334.

[3] E.A. Metzbower, P.E. Denney, D.W. Moon, C.R. Feng and S.G. Lambrakos, Mater. Sci. Forum 426-432 (2003) 4147.

[4] E.A. Metzbower and D.W. Moon, Sci. Technol. Weld. Join. 12 (2007) 189.

[5] M. Naderi, A. Saeed-Akbari and W. Bleck, Mater. Lett. 62 (2008) 1132.

[6] M. Naderi, A. Saeed-Akbari and W. Bleck, Mater. Sci. Eng. A 487 (2008) 445.

[7] S. Aslanlar, A. Ogur, U. Ozsarac, E. Ilhan and Z. Demir, Mater. Des. 28 (2007) 2

[8] N. Kahraman, Mater. Des. 28 (2007) 420.

[9] D. Ozyurek, Mater. Des. 29 (2008) 597.

[10] M. Vural, A. Akkus and B. Eryurek, J. Mater. Process. Technol. 176 (2006) 127.

[11] X.S. Liao, X.D. Wang, Z.H. Guo, M. Wang, Y.X. Wu and Y.H. Rong, Mater. Charact. 61 (2010) 341.

[12] P. Marashi, M. Pouranvari, S. Amirabdollahian, A. Abedi and M. Goodarzi, Mater. Sci. Eng. A 480
(2008) 175

[13] M. Pouranvari, S.M. Mousavizadeh, S.P.H. Marashi, M. Goodarzi and M. Ghorbani, Mater. Des. 32 (2011) 1390.

[14] Recommended Practices for Test Methods and Evaluation the Resistance Spot Welding Behavior of Automotive Sheet Steels, ANSI/AWS/SAE D8.9-97.

[15] H. Ghazanfari, M. Naderi, M. Iranmanesh, M. Seydi and A. Poshteban, Mater. Sci. Eng. A 534 (2012) 90.

[16] S. Kou, Welding Metallurgy, John Wiley \& Sons, Inc, 2nd ed., 2003.

[17] H. Zhang and J. Senkara, Resistance Welding: Fundamentals and Applications, CRC Group, Boca Raton, FL, 2006

[18] M.I. Khan, M.L. Kuntz, E. Biro and Y. Zhou, Mater. Trans. 49 (2008) 1629.

[19] M. Goodarzi, S.P.H. Marashi and M. Pouranvari, J. Mater. Process. Technol. 209 (2009) 4379.

[20] R.B. Hirsch, Weld J. 72(3) (1993) 47.

[21] A. Hasanbasoglu and R. Kacar, Mater. Des. 28 (2007) 1794. 